\title{
Gonadal Steroids Regulate Dendritic Spine Density in Hippocampal Pyramidal Cells in Adulthood
}

\author{
Elizabeth Gould, Catherine S. Woolley, Maya Frankfurt, and Bruce S. McEwen \\ Laboratory of Neuroendocrinology, The Rockefeller University, New York, New York 10021
}

\begin{abstract}
Gonadal steroids are known to influence hippocampal physiology in adulthood. It is presently unknown whether gonadal steroids influence the morphology of hippocampal neurons in the adult intact rat brain. In order to determine whether female sex hormones influence hippocampal morphology in the intact adult, we performed Golgi impregnation on brains from ovariectomized rats and ovariectomized rats which received estradiol or estradiol and progesterone replacement. Removal of circulating gonadal steroids by ovariectomy of adult female rats resulted in a profound decrease in dendritic spine density in CA1 pyramidal cells of the hippocampus. Estradiol replacement prevented the observed decrease in dendritic spine density; progesterone augmented the effect of estradiol within a short time period $(5 \mathrm{hr})$. Ovariectomy or gonadal steroid replacement did not affect spine density of CA3 pyramidal cells or granule cells of the dentate gyrus. These results demonstrate that gonadal steroids are necessary for the maintenance of normal adult CA1 hippocampal pyramidal cell structure. The short time course required to observe these effects ( $3 \mathrm{~d}$ for the estradiol effect and 5 $\mathrm{hr}$ for the progesterone effect) implies that CA1 pyramidal cell dendritic spine density may fluctuate during the normal (4-5 d) rat estrous cycle.
\end{abstract}

It is now known that levels of circulating steroid hormones during development and in adulthood play a critical role in determining physiology and behavior in adulthood. The neural mechanisms underlying hormonal effects on brain function have been the subject of numerous studies. Traditionally, steroid hormone effects have been divided into 2 categories, organizational and activational (see Arnold and Gorski, 1984, for review). Whereas organizational effects have been defined as permanent structural changes induced by hormones during development, activational effects have been defined as the turning on or off of previously established neural circuits in adulthood (Arnold and Gorski, 1984). The original view of steroid hormone effects on the brain indicated that activation does not involve morphologic alterations (see Arnold and Breedlove, 1985, for commentary). Evidence accumulated over the past decade, however, has demonstrated that manipulation of steroid hormone levels can induce dramatic structural changes in sexually dimorphic

\footnotetext{
Received June 26, 1989; revised Sept. 29, 1989; accepted Oct. 6, 1989.

This research was supported by NS 07080 and the Richard Lounsbery Foundation.

Correspondence should be addressed to Elizabeth Gould, Box 290, Laboratory of Neuroendocrinology, Rockefeller University, 1230 York Ave., New York, NY 10021.

Copyright (C) 1990 Society for Neuroscience $0270-6474 / 90 / 041286-06 \$ 02.00 / 0$
}

regions which subserve reproductive behavior, such as neurons of the adult avian song system (DeVoogd and Nottebohm, 1981; DeVoogd et al., 1985) and the mammalian spinal cord (Breedlove and Arnold, 1981; Kurz et al., 1986) and hypothalamus (Carrer and Aoki, 1982; Bloch and Gorski, 1988). Since the morphologic characteristics of neurons have been shown to influence the functional characteristics of neurons (Enoka and Stuart, 1984; Purves, 1988), it is likely that these hormoneinduced structural changes contribute significantly to the activation of neural circuits necessary for certain behaviors.

The mammalian hippocampal formation has been shown to be involved in a number of important functions including cognitive processes (Olton, 1983; Squire, 1983), gonadotropin release (Carrillo, 1981), and puberty intitiation (Willoughby and Martin, 1978). An understanding of the chemical factors which are required for the normal function of this neural region will shed light on the physiological and anatomical substrates underlying thesc proccsscs. Ncurons of the adult hippocampal formation appear to be particularly sensitive to gonadal steroids as alterations in levels of female sex hormones dramatically change hippocampal physiology (Woolley and Timiras, 1962; Terasawa and Timiras, 1968; Kawakami et al., 1970; Teyler et al., 1980). It is not known, however, if manipulations in ovarian steroid levels also influence the structure of adult hippocampal neurons.

In an effort to determine whether the morphologic characteristics of hippocampal neurons are also affected by changes in the circulating levels of female sex hormones, we examined the effect of manipulations in ovarian steroids on the density of dendritic spines from 2 portions of the dendritic tree of 3 different neuronal populations of the hippocampal formation: pyramidal cells from the CAI region, pyramidal cells from the $\mathrm{CA} 3$ region, and granule cells from the dentate gyrus.

\section{Materials and Methods}

Twenty-four virgin female Sprague-Dawley (Charles River) rats (200$220 \mathrm{gm}, 75 \mathrm{~d}$ old) were used for this study. Six of these rats were used as intact controls. The remaining 18 rats were ovariectomized (OVX) under Metofane anesthesia and killed one week later. These animals were assigned to one of the following treatment groups during the interval between surgery and death: (1) beginning $3 \mathrm{~d}$ after surgery, $6 \mathrm{OVX}$ rats received 2 subcutaneous injections of estradiol benzoate $(E, 10 \mu \mathrm{g} /$ $0.1 \mathrm{ml}$ in sesame oil) $24 \mathrm{hr}$ apart. Five hours prior to death (48 $\mathrm{hr}$ after the last $E$ injection), these rats received a single injection of progesterone (P, $500 \mu \mathrm{g} / 0.1 \mathrm{ml}$ in sesame oil); (2) 6 OVX rats received the same $\mathrm{E}$ injection regimen as described above and a single injection of the vehicle alone in place of P; or (3) $6 \mathrm{OVX}$ rats received injections of the vehicle alone at all time points described above.

These rats were perfused and the brains were processed using a modified version of the single-section Golgi-impregnation method. All rats were deeply anesthetized with Ketalar (ketamine $\mathrm{HCl}$ ) and transcardially 


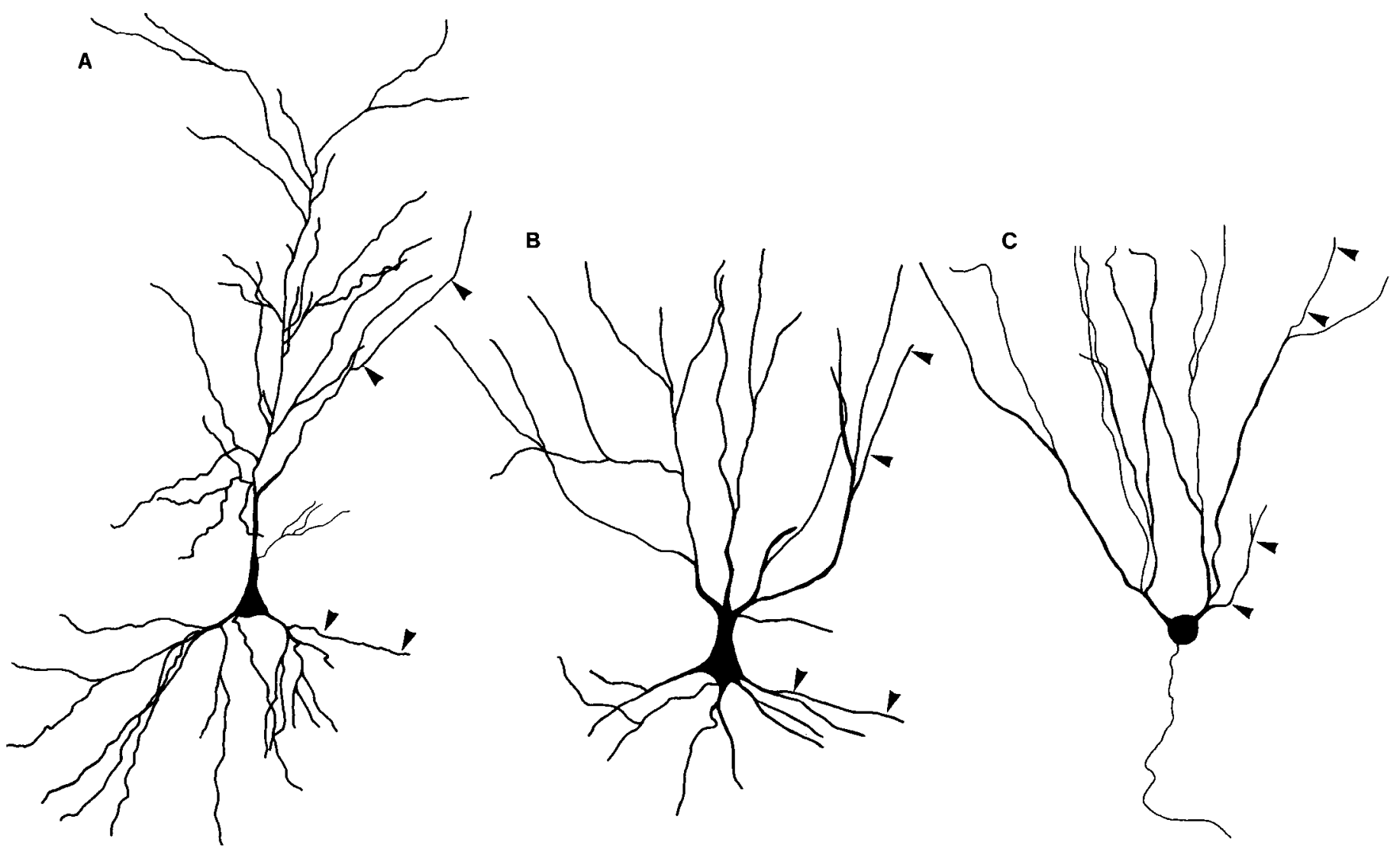

Figure 1. Camera lucida tracings $(\times 1250)$ of a representative CA1 pyramidal cell $(A)$, C.A3 pyramidal cell $(B)$, and dentate gyrus granule cell $(C)$. The regions located between the arrowheads demonstrate dendritic segments appropriate for analysis (see text).

perfused with $100-150 \mathrm{ml} \mathrm{4 \%}$ paraformaldehyde in $0.1 \mathrm{M}$ phosphate buffer with $15 \%$ picric acid. Brains were postfixed for $24 \mathrm{hr}$ in a solution of the same composition as the perfusate. Coronal sections $100 \mu \mathrm{m}$ thick were cut by use of a Vibratome in a bath of $3 \%$ potassium dichromate in distilled water and stored in this solution for $24 \mathrm{hr}$. Following this, the sections were rinsed in distilled water and mounted onto ungelatinized slides. Coverslips were glued over the tissue sections at the 4 corners and the slide assemblies were placed in $1.5 \%$ silver nitrate in distilled water for $24 \mathrm{hr}$ in the dark. The slide assemblies were then dismantled, and the sections were rinsed in distilled water, dehydrated, cleared, and coverslipped.

The slides containing Golgi-impregnated brain sections were coded prior to quantitative analysis. The code was not broken until after the analysis was completed. In order to be selected for analysis, Golgiimpregnated hippocampal cells had to possess the following characteristics: (1) location within the dorsal portion of the CA1 or CA3 hippocampal fields for pyramidal cells or the dentate gyrus for granule cells, (2) relative isolation from neighboring impregnated cells in order to allow identification of dendrites which emanated from specific cells, and (3) dark and consistent impregnation throughout the extent of the neuron. These selection criteria were employed in an effort to analyze neurons from the same populations within and between groups. For each selected neuron, the cross-sectional cell body area was determined by use of an image-analysis morphometry program (Southern Micro Instrument Inc., Atlanta, GA). In addition, 2 measurements of spine density were obtained from specific regions of the dendritic tree for each neuron. For each pyramidal cell, spine density was determined from the most lateral tertiary dendrite on the apical tree and the most lateral secondary dendrite on the basal tree (see Fig. 1). These dendrites were always located within the stratum lacunosum moleculare and the stratum oriens of Ammon's horn, respectively. For each granule cell, spine density values were obtained from segments of dendrites which were proximal to the cell body and those which were distal to the cell body. The latter granule cell spine density value was always obtained from the longest dendrite (see Fig. 1). These dendrites were located in the inner and outer molecular layers of the dentate gyrus, respectively. The criteria by which dendritic segments were selected for analysis were used to reduce the possibility that we were comparing spine density from different portions of the dendritic tree within and between animals. Camera lucida tracings $(1250 \times)$ were obtained from selected dendritic segments that remained within the plane of focus. All spines of the selected dendritic segment were counted, the length of the segment was determined with the SMI image analysis system, and spine density values were expressed as number of spines $/ 10 \mu \mathrm{m}$ of dendrite. For each animal, a total of 36 dendritic branches was analyzed (12 for each of the 3 cell types). The means of each variable were determined for each animal, and these data were subjected to a 1-way ANOVA with Tukey HSD post hoc comparisons.

\section{Results}

Light microscopic examination of Golgi-impregnated tissue revealed reliable and consistent staining throughout the hippocampus for all brains. In particular, the 3 neuronal populations of interest in the present study-CA1 pyramidal cells, CA3 pyramidal cells, and dentate gyrus granule cells - were always well represented and easily identifiable in the Golgi stained sections. Quantitative analysis of CA1 pyramidal cells revealed significant changes in the density of apical dendritic spines $(F[3,20]$ $=26.68, p<0.00001)$. One week after surgery, OVX rats which did not receive hormone replacement showed significantly fewer apical dendritic spines in the CAl region than intact female rats $(p<0.01$; Fig. 2, Table 1). The decrease in apical dendritic spines was prevented by 2 injections of $E$, in that the spine density in this region was no longer significantly different from 


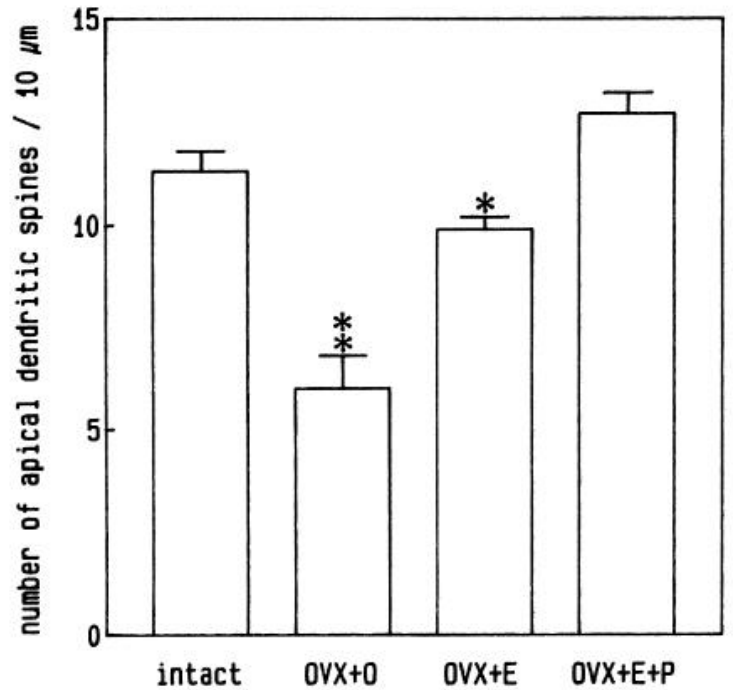

Figure 2. Number of dendritic spines $/ 10 \mu \mathrm{m}$ dendrite obtained from the apical portion of the CAl pyramidal cell dendritic tree. Values represent mean + SEM. Two asterisks denote significant difference from intact female, OVX $+\mathrm{E}$ and OVX $+\mathrm{E}+\mathrm{P}(p<0.01)$. One asterisk indicates significant difference from $\mathrm{OVX}+\mathrm{E}+\mathrm{P}$ group $(p<0.05)$.

the intact female (Fig. 2, Table 1). The effect of E replacement on spine density was significantly enhanced by the administration of a single dose of $\mathrm{P} 5 \mathrm{hr}$ prior to sacrifice $(p<0.05$; Fig. 2 , Table 1). In addition to changes in the number of spines per length of dendrite, the shape of these spines appeared to be different across treatment groups. Apical dendritic spines of the CA1 region from OVX animals which did not receive hormonal replacement showed fewer and less pronounced heads compared with intact females and hormone replaced females. The greatest difference in spine shape was observed between the OVX animals that received no hormones and those that received both $\mathrm{E}$ and $\mathrm{P}$ (Figs. 3, 4).

Quantitative analysis of spine density in the basal dendrites of CA1 pyramidal cells also revealed significant changes $(F[3,20]$ $=3.74, p<0.03$ ) which were less dramatic than those observed for the dendritic spines of the apical tree. OVX animals which did not receive hormone replacement showed a decrease in mean spine density of basal CA1 pyramidal cell dendrites (Table 1). Although this decrease was not significantly different from the intact female $(p<0.1)$, replacement of $\mathrm{E}$ and $\mathrm{P}$ to OVX animals resulted in a trend toward an increase in dendritic spine density compared with intact females. Significant differences in basal dendritic spine density were detected between the OVX rats which did not receive hormone replacement and those which received both $\mathrm{E}$ and $\mathrm{P}(p<0.05$; Table 1$)$. No obvious changes in the shape of dendritic spines were observed in the basal dendritic region for any treatment condition. In addition, no significant changes between groups were observed in cross-sectional cell body area for CA1 pyramidal cells (Table 2).

The cross-sectional cell body area of granule and CA3 pyramidal cells was also unchanged in any of the treatment groups examined in this study (Table 2). The observations that cell body area did not significantly differ between groups support the notion that the neurons we selected for analysis were chosen from the same populations across treatment groups.

In contrast to the changes in spine density observed for CA1 pyramidal cells, quantitative analysis of spine density of $\mathrm{CA} 3$ pyramidal cells showed no significant changes in either the apical
Figure 3. Photomicrograph montage of representative apical dendrites from CAl pyramidal cells of OVX animals treated with the vehicle alone $(A)$ or $\mathrm{E}$ and $\mathrm{P}(B)$. Observe the increase in dendritic spine density in $B$ compared to A. Arrows indicate dendritic spines with pronounced heads. The entire extent of these dendrites in a single brain section, designated by the same letters, is shown in Figure 4. Scale bar, $10 \mu \mathrm{m}$ (applies to both $A$ and $B$ ).
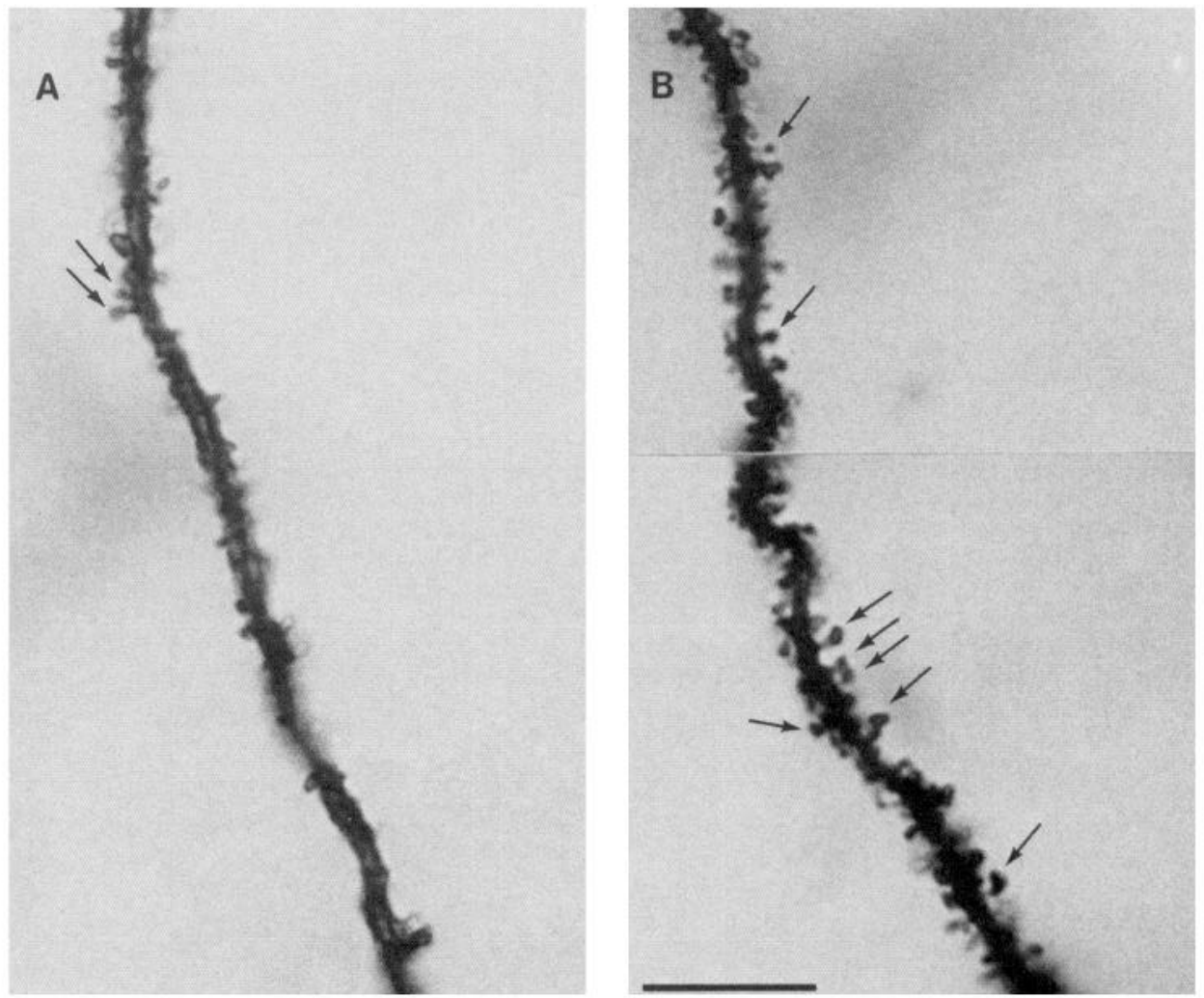


\begin{tabular}{|c|c|c|c|c|}
\hline \multirow[b]{2}{*}{ Neural region } & \multicolumn{4}{|l|}{ Spines $/ 10 \mu \mathrm{m}$} \\
\hline & Intact female & $\mathrm{OVX}+\mathrm{O}$ & $\mathrm{OVX}+\mathrm{E}$ & $\begin{array}{l}\mathrm{OVX}+\mathrm{E} \\
+\mathrm{P} \\
\end{array}$ \\
\hline CA1 pyramidal cell apical dendrites (stratum lacunosum molcculare) & $11.3 \pm 0.5$ & $6.0 \pm 0.8^{\prime \prime}$ & $9.9 \pm 0.3^{h}$ & $12.7 \pm 0.5$ \\
\hline CAl pyramidal cell basal dendrites (stratum oriens) & $8.0 \pm 0.6$ & $5.6 \pm 1.0^{b}$ & $7.4 \pm 0.3$ & $9.1 \pm 0.9$ \\
\hline CA3 pyramidal cell apical dendrites (stratum lacunosum moleculare) & $11.8 \pm 0.8$ & $10.1 \pm 0.6$ & $10.2 \pm 0.6$ & $11.9 \pm 0.5$ \\
\hline CA3 pyramidal cell basal dendrites (stratum oriens) & $7.5 \pm 0.6$ & $9.7 \pm 0.9$ & $7.6 \pm 0.7$ & $9.7 \pm 0.8$ \\
\hline Granule cell proximal dendrites (inner molecular layer) & $5.1 \pm 0.6$ & $6.3 \pm 1.3$ & $6.6 \pm 0.9$ & $7.2 \pm 1.0$ \\
\hline Granule cell distal dendrites (outer molecular layer) & $8.2 \pm 0.8$ & $7.6 \pm 1.3$ & $8.5 \pm 0.9$ & $8.9 \pm 0.7$ \\
\hline
\end{tabular}

Data represent means \pm SEM and were analyzed with 1 -way analysis of variance with post hoc comparisons made with the Tukey HSD test.

"Significant difference from OVX $+\mathrm{E}+\mathrm{P}$, as well as from intact female, $p<0.01$.

"Significant difference from OVX $+\mathrm{E}+\mathrm{P}, p<0.05$. (All other comparisons were not significant.)

or the basal dendrites. Furthermore, no significant changes were observed for dendritic spine density of granule cell proximal or distal dendrites ( $p>0.05$ for all comparisons, Table 1).

\section{Discussion}

\section{Effects of gonadal steroids on dendritic spines}

These data demonstrate that female sex hormones modulate the number and shape of dendritic spines on a specific population of neurons in the adult mammalian hippocampus. Removal of circulating gonadal steroids by gonadectomy resulted in a decrease in CAl pyramidal cell dendritic spine density that was prevented with estradiol treatment. The effect of estradiol on spine density was further augmented by progesterone. No changes were observed in dendritic spine density of granule cells or CA3 pyramidal cells suggesting that this effect may be specific to CA1 neurons within the hippocampus. The presence of some estradiol receptors (Loy et al., 1988), as well as estrogen-inducible progesterone receptors (Parsons et al., 1982) in the CAl region indicates that the oberved changes in spine density with OVX and hormone replacement may be direct genomic effects of gonadal steroids on CAl pyramidal cells. Some pyramidal cells of the CA3 region, however, also concentrate estradiol (Loy et al., 1988), but no apparent change in spine density was observed in these neurons in the present study. It is also clear from these results that the entire CAl pyramidal cell is not uniformly responsive to these hormone manipulations; more dramatic changes were noted in the density of spines on apical dendrites than on basal dendrites. Moreover, OVX and hormone replacement caused changes in the shape of apical dendritic spines but not in the shape of basal dendritic spines. These observations raise the possibility of at least 2 different, but not mutually exclusive, interpretations: (1) in the CAl region, apical dendritic spines are inherently more plastic than basal dendritic spincs and respond more dramatically to variations in gonadal steroid levels, or (2) an estrogen-sensitive afferent population, which forms synapses primarily on the apical tree, plays a role in modulating spine density and shape.

With regard to the latter possibility, it is interesting that a variety of afferents to the hippocampus form synapses on sharply defined regions of CA1 pyramidal cells (Bayer, 1985) and developmental and deafferentation studies suggest that afferent input strongly influences the shape and number of dendritic spines (Hammori, 1973; Benshalom and White, 1988). There are a number of sources from which indirect effects could arise: CA3 pyramidal cells, cells of the raphe nuclei, the locus ceruleus, the entorhinal cortex, and/or the medial septum/diagonal band (Bayer, 1985). Several lines of evidence suggest that cholinergic afferents, arising from the nucleus of the diagonal band, may play such a role because (1) a subpopulation of these neurons responds to estradiol with significant increases in activity of the cholinergic synthetic enzyme, choline acetyltransferase (ChAT) (Luine, 1985); (2) a similar estradiol-induced increase in ChAT activity is noted in the CAl region of the hippocampus (Luine, 1985), a projection region of these neurons (Bayer, 1985); and (3) light and clectron microscopic studics of CAl pyramidal cells suggest that cholinergic axons which arise from the septal/ diagonal band region more commonly form synapses on apical dendrites than basal dendrites (Frotscher and Leranth, 1983; Matthews et al., 1987).

A
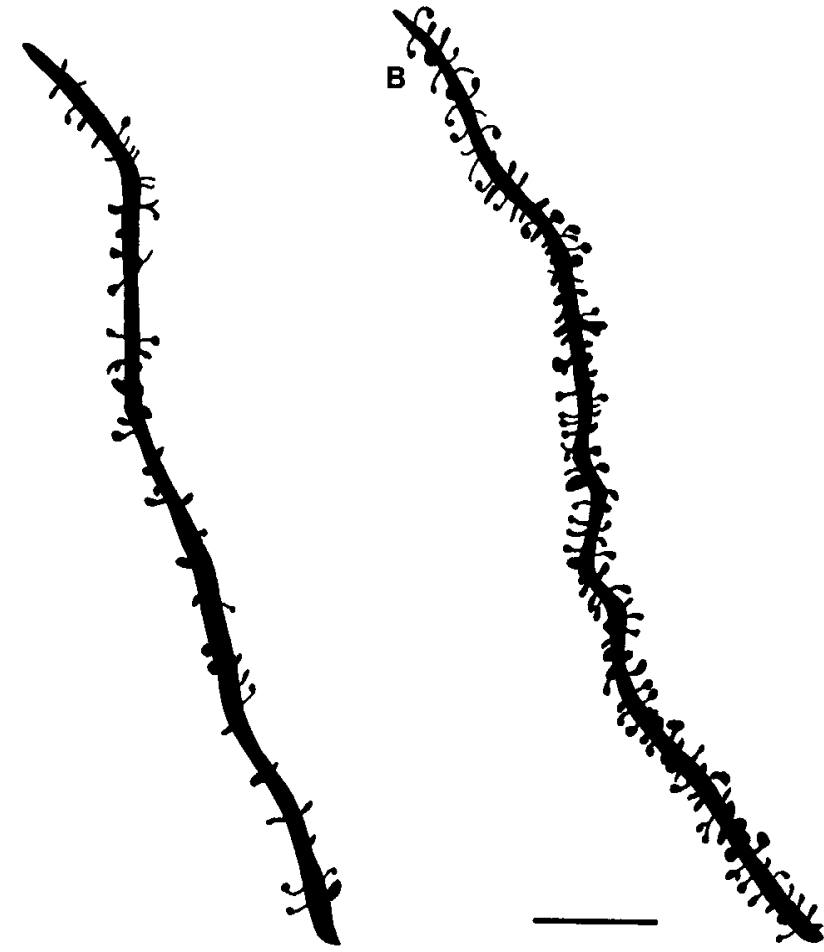

Figure 4. Camera lucida drawings of the apical dendrites partially depicted in Figure 3. Observe the increase in dendritic spines with pronounced heads in $B$ compared to $A$. Scale bar, $10 \mu \mathrm{m}$ (applies to both $A$ and $B$ ). 
Table 2. Cross-sectional cell body area

\begin{tabular}{lllll} 
& \multicolumn{4}{l}{ Area $\left(\mu \mathrm{m}^{2}\right)$} \\
\cline { 2 - 5 } Neuron type & Intact female & OVX $+\mathrm{O}$ & OVX $+\mathrm{E}$ & OVX $+\mathrm{E}+\mathrm{P}$ \\
\hline CA1 pyramidal cell & $215.5 \pm 8.0$ & $201.9 \pm 8.4$ & $217.3 \pm 23.5$ & $210.8 \pm 6.4$ \\
CA3 pyramidal cell & $392.7 \pm 11.7$ & $394.1 \pm 9.3$ & $380.8 \pm 23.0$ & $370.3 \pm 16.3$ \\
Granule cell & $183.2 \pm 5.2$ & $181.6 \pm 6.9$ & $170.6 \pm 5.4$ & $177.6 \pm 5.2$
\end{tabular}

Data represent means \pm SEM and were analyzed with 1 -way analysis of variance with post hoc comparisons made with the Tukey HSD test. No significance in overall differences or post hoc comparisons was observed.

Meyer and colleagues (1978) have shown that dendritic spine density of CA1 pyramidal cells undergoes a marked increase at puberty in male mice. Castration at postnatal day 20 prevents this increase, and androgen replacement prevents the castration effect. These results suggest that CA1 pyramidal cell dendritic spine density may be dependent on gonadal steroids in adult males as well.

\section{Functional implications}

Dendritic spines are thought to represent postsynaptic sites (Fifkova, 1985). Since changes in the number and shape of dendritic spines during development or in response to experimentally induced injury have been correlated positively with changes in synapses (Parnavelas et al., 1974; Matthews et al., 1976), it is likely that the spine changes observed in this report reflect changes in synapses and, thus, changes in the excitability of CAl pyramidal cells. Previous studies have shown that increases in circulating levels of cstradiol induced experimentally or during proestrus result in increased neuronal excitability in the hippocampus (Woolley and Timiras, 1962; Terasawa and Timiras, 1968; Kawakami et al., 1970). Although the behavioral implications of this phenomenon remain unknown, it is possible that morphologic changes induced by gonadal steroids would affect a number of processes, such as gonadotropin release (Carrillo, 1981) and learning (Olton, 1983; Squire, 1983), which have been attributed to this neural region.

The short time course required to observe these changes ( $3 \mathrm{~d}$ for the estradiol effect and $5 \mathrm{hr}$ for the progesterone effect) is particularly noteworthy because levels of circulating gonadal steroids vary normally during the $4-5 \mathrm{~d}$ rat estrous cycle (Terasawa and Timiras, 1968). These results imply that CAl pyramidal cells may constantly undergo dendritic and synaptic remodeling during the course of the estrous cycle, a conjecture that is compatible with recent observations that rat sympathetic ganglion neurons normally exhibit a high degree of dendritic plasticity (Purves et al., 1986; Purves, 1988).

\section{References}

Arnold, A. P., and S. M. Breedlove (1985) Organizational and activational effects of sex steroids on brain and behavior: A reanalysis. Horm. Behav. 19: 469-498.

Arnold, A. P., and R. A. Gorski (1984) Gonadal steroid induction of structural sex differences in the CNS. Annu. Rev. Neurosci. 7:413442.

Bayer, S. A. (1985) The hippocampus. In The Rat Nervous System, G. Paxinos, ed., pp. 335-352, Academic, Sydney.

Benshalom, G., and E. L. White (1988) Dendritic spines are susceptible to structural alterations induced by degeneration of their presynaptic afferents. Brain Res. 443: 377-382.

Bloch, G. J., and R. A. Gorski (1988) Estrogen/progesterone treatment in adulthood affects the size of several components of the medial preoptic area in the male rat. J. Comp. Neurol. 275: 613-622.
Breedlove, S. M., and A. P. Arnold (1981) Sexually dimorphic motor nucleus in rat spinal cord: Response to adult hormone manipulation, absence in androgen insensitive rats. Brain Res. 225: 297-307.

Carrer, H. F., and A. Aoki (1982) Ultrastructural changes in the hypothalamic nucleus of ovaricetomized rats after cstrogen treatment. Brain Res. 240: 221-223.

Carillo, A. J. (1981) Stimulation of the hippocampus and ovulation in the rat: Specific or nonspecific effects. Neuroendocrinology 33:223229.

DeVoogd, T., and F. Nottebohm (1981) Gonadal hormones induce dendritic growth in the adult avian brain. Science 214: 202-204.

DeVoogd, T., B. Nixdorf, and F. Nottebohm (1985) Synaptogenesis and changes in synaptic morphology related to acquisition of a new behavior. Brain Res. 329: 304.

Enoka, R. M., and D. G. Stuart (1984) Henneman's "size principle." Current issues. Trends Neurosci. 7: 226-228.

Fifkova, E. (1985) A possible mechanism of morphometric changes in dendritic spines induced by stimulation. Cell Mol. Neurobiol. 5. 47-63.

Frotscher, M., and C. Leranth (1983) Cholinergic innervation of the rat hippocampus as revealed by choline acetyltransferase immunocytochemistry: A combined light and electron microscopic study. J. Comp. Neurol. 239: 237-246.

Hammori, J. (1973) The inductive role of presynaptic axons in the development of postsynaptic spines. Brain Res. 62: 337-344.

Kawakami, M., E. Terasawa, and T. Ibuki (1970) Changes in multiple unit activity of the brain during the estrous cycle. Neuroendocrinology 6: $30-48$.

Kurz, E. M., D. R. Sengelaub, and A. P. Arnold (1986) Androgens regulate dendritic length of sexually dimorphic mammalian motor neurons in adulthood. Science 232: 395.

Loy, R., J. L. Gerlach, and B. S. McEwen (1988) Autoradiographic location of estradiol-binding neurons in the rat hippocampal formation and entorhinal cortex. Dev. Brain Res. 39: 245-251.

Luine, V. N. (1985) Estradiol increases choline acetyltransferase activity in specific basal forebrain nuclei and projection areas of female rats. Exp. Neurol. 89: 484-490.

Matthews, D. A., C. Cotman, and G. Lynch (1976) An electron microscopic study of lesion-induced synaptogenesis in the dentate gyrus of the adult rat. II. Reappearance of morphologically normal synaptic contacts. Brain Res. 115: 23-41.

Matthews, D. A., P. M. Salvaterra, G. D. Crawford, C. R. Houser, and J. E. Vaughn (1987) An immunocytochemical study of choline acetyltransferase containing neurons and axon terminals in normal and partially deafferented hippocampal formation. Brain Res. 402: 3043.

Meyer, G., R. Ferres-Torres, and M. Mas (1978) The effects of pubcrty and castration on hippocampal dendritic spines of mice. Brain Res. 155: 108-112.

Olton, D. D. S. (1983) Memory functions and the hippocampus. In Neurobiology of the Hippocampus, W. Seifert, ed., pp. 335-373, Academic, London.

Parnavelas, J. G., G. Lynch, N. Brecha, C. W. Cotman, and A. Globus (1974) Spine loss and regrowth in hippocampus following deafferentation. Nature 248: 71-73.

Parsons, B., T. C. Rainbow, N. J. MacLusky, and B. S. McEwen (1982) Progestin receptor levels in rat hypothalamic and limbic nuclei. J. Neurosci. 2: 1446-1452.

Purves, D. (1988) In Body and Brain, A Trophic Theory of Neural Connections, Harvard U. P., Cambridge, MA.

Purves, D., R. D. Hadley, and J. T. Voyvodic (1986) Dynamic changes in the dendritic geometry of individual neurons visualized over pe- 
riods of up to three months in the superior cervical ganglion of living mice. J. Neurosci. 6: 1051-1060.

Squire, L. R. (1983) The hippocampus and the neuropsychology of memory. In Neurobiology of the Hippocampus, W. Seifert, ed., pp. 491-511, Academic, London.

Terasawa, E., and P. S. Timiras (1968) Electrical activity during the estrous cycle of the rat: Cyclic changes in limbic structures. Endocrinology 83: 207-216.

Teyler, T. J., R. M. Vardaris, D. L. Lewis, and A. B. Rawitch (1980)
Gonadal steroids: Effects on excitability of hippocampal pyramidal cells. Science 209: 1017-1019.

Willoughby, J. O., and J. B. Martin (1978) The role of the limbic system in neuroendocrine regulation. In Limbic Mechanisms, K. E. Livingston and $O$. Hornykiewicz, ed., Plenum, New York.

Woolley, D. E., and P. S. Timiras (1962) The gonad-brain relationship: Effects of female sex hormones on electroshock convulsions in the rat. Endocrinology 70: 196-200. 